\title{
Correction to: Production and characterization of polyhydroxyalkanoates from industrial waste using soil bacterial isolates
}

\author{
Shreya Shah ${ }^{1} \cdot$ Anil Kumar $^{1}$ iD \\ Published online: 20 March 2021 \\ (C) Sociedade Brasileira de Microbiologia 2021
}

\section{Correction to: Brazilian Journal of Microbiology https://doi.org/10.1007/s42770-021-00452-z}

In the original publication of the article, the last sentence in the acknowledgment was missing.

The correct acknowledgment is as below.

SS is grateful to the Devi Ahilya University, Indore, for the award of the Golden Jubilee Fellowship. The authors acknowledge the facilities of the Department of Biotechnology, Ministry of Science and Technology, Government of India, New Delhi (DBT), under the Bioinformatics Sub Centre as well as M.Sc. Biotechnology program present in our School of Biotechnology and used in the present work.

Authors acknowledge the facilities of FTIR and XRD at the Inter University Consortium, UGC-DAE available in our University campus used in the present work.

Publisher's note Springer Nature remains neutral with regard to jurisdictional claims in published maps and institutional affiliations.
The online version of the original article can be found at https://doi.org/ 10.1007/s42770-021-00452-z

Anil Kumar

ak_sbt@yahoo.com

1 School of Biotechnology, Devi Ahilya University, Khandwa Road, Indore 452001, India 